\title{
Recover Overnight? \\ Work Interruption and Worker Productivity
}

\author{
Xiqian Cai, Jie Gong, Yi Lu, and Songfa Zhong* \\ National University of Singapore
}

This Version: March 2015

\begin{abstract}
This paper investigates whether and how work interruption influences workers' subsequent productivity in the setting of machine breakdown. The study utilizes a data set of individual productivity and machine conditions, where each worker faces a chance that her machine breaks down randomly on a daily basis. The analysis finds that compared with a workday with smooth production, experiencing machine breakdown is associated with a decline in individual productivity the following day. The paper discusses possible explanations, including proficiency loss and negative emotion induced by work interruption, for the observed effect. The findings suggest the importance of understanding and managing interruption in the workplace, and contribute to unfolding the hidden determinants of productivity at the micro level.
\end{abstract}

Keywords: Productivity, Labor supply, Work interruption

JEL Classification: D84, J22, M11

\footnotetext{
${ }^{*}$ Cai(xiqiancai@u.nus.edu), Lu(ecsluyi@nus.edu.sg), Zhong(ecszs@nus.edu.sg): Department of Economics, National University of Singapore, 1 Arts Link, Singapore 117570. Gong(gong@nus.edu.sg): Department of Strategy and Policy, NUS Business School, 15 Kent Ridge Dr., Singapore 119245. We thank seminar and conference participants at National University of Singapore and 5th Annual Xiamen University International Workshop on Experimental Economics (2014) for helpful comments. We would also like to acknowledge the financial support from Singapore Ministry of Education Academic Research Fund Tier 1.
} 


\section{Introduction}

Interruptions are common in workplaces and costly to individuals, firms, and organizations. From equipment breakdown to unscheduled meetings and communication requests, unplanned breaks from the ideal smooth and continuous production lead to losses in work hours and reductions in worker productivity. For instance, according to Spira and Feintuch (2005), the direct costs of unnecessary interruptions have been estimated at an average of 28 percent of daily time for knowledge workers in the United States. Nowadays, with firms adopting modern organization and communication technologies-open-plan offices, e-mails, instant messages, etc.-managing interruption has become increasingly important and challenging for businesses and their workers.

In addition to direct productivity impairment, work interruption may have spillover effects on subsequent production. On the one hand, it has been widely recognized that interruptions could have negative spillovers: workers may need extra time to warm up and restore full engagement and concentration; productivity may decline due to negative emotions, such as the stress from time pressure and frustration from failing to meet targets (Mandler 1990). ${ }^{1}$ On the other hand, interruptions may be beneficial for subsequent productivity as occasional breaks could help workers alleviate fatigue and boredom (Roy 1959). Moreover, workers might try to make up for the losses caused by interruptions and exert greater effort leading to increased productivity (Camerer, Babcock, Loewenstein and Thaler 1997). In the field of management and organization sciences, both positive and negative effects of interruptions have been discussed extensively (see, Jett and George 2003, for a review). Nevertheless, there is scant empirical work estimating the consequences of work interruption, partly because of the difficulty of identifying each incident and establishing a causal relationship.

This paper is the first to estimate the effect of interruption on workers' subsequent productivity using exogenous incidents of work interruption. Specifically, we collect a data set of worker-level daily output from a plastic printing company in China. Our sample spans over a period of 473 days, during which a total number of 273 workers labored on 75 machines for 25 different products. As the workers are paid by piece-rate, we have an accurate record of workers' daily output levels. On a daily basis, team managers assign each worker to a machine and a product type, and each worker faces the chance that machine would break down. On average, machines have a breakdown frequency of $14 \%$, and each breakdown takes

\footnotetext{
${ }^{1}$ In the workplace, it has been observed that negative shocks, such as failures in salary negotiation (Mas 2006), bonus payments falling short of individually assigned bonus targets (Ockenfels, Sliwka and Werner 2014), and bereavement and family illness (Oswald, Proto and Sgroi 2014) affect workers' subsequent productivity.
} 
about 4 hours to repair. As machine breakdown is in general random for each worker on a specific workday, we can estimate the causal effect of machine breakdown on subsequent productivity. $^{2}$

More specifically, we estimate how machine breakdown affects a worker's productivity the following day, and find that it leads to a 2 percent decline in the worker's daily output. This result is robust to the inclusion of various characteristics of the machine and the worker, and a battery of fixed effects (worker, product-day, and product-machine fixed effects). Further examining our identifying assumptions, we waive concerns about manipulation of production assignment by team managers and manipulation of machine breakdowns by workers; we also address the possibility of the omitted variables bias adopting two separate placebo tests.

Our findings domenstrate a robust, negative spillover effect from work interruption. We provide further discussion about possible sources of the observed effect. First, it is possible that workers may become less proficient and less engaged after the interruption, and need to start over with the techniques and procedures. Second, the observed effect may come from a negative response or emotion toward the negative shock. We conduct some further empirical analyses and show evidence consistent with these two possible sources of reduced productivity.

Exploring worker heterogeneity, we find that the effect is similar across worker age, while the effect is larger, although not statistically significant, among males than females, and among migrants than local workers. We also find that when there are fewer peers experiencing interruptions, the negative effect to a worker's subsequent productivity is larger, lending support to the literature on social comparison in the workplace (Mas and Moretti 2009; De Grip and Sauermann 2012; Guryan, Kroft and Notowidigdo 2009).

Our study contributes to a growing literature on the economic consequences of work interruption. Researchers have investigated various forms of interruptions in workplaces, including worker absence, menstruation, weather and pollution. Herrmann and Rockoff (2012b) use unique data on worker absence to estimate the effect of work absences on productivity. They find that expected loss in daily productivity from employing a temporary substitute is on par with replacing a regular worker of average productivity with a worker of 10-20 percent worse productivity. Ichino and Moretti (2009) observe that menstruation as a form of interruption contributes to gender gaps in absenteeism and earnings, while Herrmann and Rockoff (2012a, 2013) find little support for the role of menstruation in explaining the gender gap in earnings. Connolly (2008) explores the effect of exogenous variation in daily

\footnotetext{
${ }^{2}$ Our data contain the information on the duration of machine breakdown, but not on the exact time period of machine breakdown, which precludes us from examining the effect of breakdown on productivity in the same day.
} 
weather on labor supply, and finds that men shift on average 30 minutes from leisure to work on rainy days, giving rise to a rough estimate of the intertemporal elasticity of labor supply at around 0.01. Zivin and Neidell (2012) use a novel panel dataset with farm workers to investigate the impact of pollution on labor supply, and find that a $10 \mathrm{ppb}$ decrease in ozone concentrations increases worker productivity by 4.2 percent. Zivin and Neidell (2014) estimate the influence of temperature on time allocation, and find that temperature increases at the higher end of the distribution reduce hours worked in industries with high exposure to climate, while temperature increases at the lower end of the distribution do not show such an effect.

Our findings are also related to income targeting and labor supply, a topic that has been extensively investigated in the recent literature. In a seminal study by Camerer et al. (1997), the authors find that cabdrivers work more on the days when the transient salary is low, which suggests that they might have a daily income target and quit working once they reach that target. Several follow-up studies use field evidence and observational data to investigate the daily income targeting hypothesis. The evidence appears to be mixed. Several studies find positive evidence of the daily income targeting hypothesis (Fehr and Goette 2007; Crawford and Meng 2011), while some suggest otherwise (Farber 2005, 2008; Andersen et al. 2014). As our data do not contain same-day productivity before and after interruption (details to be explained in the data section), we cannot directly test daily income targeting. Alternatively, our setting could be interpreted as a test of cross-day income targeting behavior, in which workers would work harder on the second day to make up for the losses in the first day. However, our results do not support this prediction, suggesting that income targeting behavior is more likely to be "one day at a time."

The rest of the paper proceeds as follows. In Section 2, we describe the context of our research setting, including the institutional background and a stylized model. In Section 3 , we discuss the data, main variables, and identification strategy. Section 4 presents our empirical estimates and robustness checks. Section 5 concludes.

\section{Context}

\subsection{Workplace}

We collect a data set of worker-level daily output from a leading company that produces double-wall paper cups in Fujian Province of China. Established in 2003, the company has become a major supplier of paper cups for food and beverage industries. In 2011, the company accounted for around 15 percent of the national market. By 2013, it had $\$ 7$ million 
in total aseets, $\$ 5$ million in annual revenue, and about 300 employees.

Our data focus on production workers in the molding and wrapping divisions. Their main task is to operate the molding machines to seal the cup body and bottom, and then use wrapping machines to bond sleeves for the paper cups. Workers are hired from both within and outside Fujian Province. Each day, workers are divided into day and night shifts, typically working for 12 hours. Within a shift, each worker is assigned a machine and a product type. A machine can generally be configured for multiple types of products, and production efficiency may differ across products.

Daily production activity is organized as follows. Each day, a general production manager determines the compositions of the production teams, which consist of a team manager and four or five workers. The composition varies each day, and is largely unknown to the team managers and workers until they arrive at the site. Team managers assign their member workers machines and product types. Notably, workers themselves do not decide on their product, machine, or team. Once assigned, workers cannot change the machine or the product. The only choice variable a worker has is how much effort to exert into running the machine and processing material for the next productive stage. Moreover, workers rotate tasks and machines, i.e., they regularly change machines and product types. As the general manager explained, the practice of random rotation reflects (1) concern about fairness, as machine efficiency varies across products, and (2) the fact that there is little room for human capital accumulation in the low-skill jobs.

Once production begins, team managers prepare packaging boxes labeled with workers' names and products, and provide assistance to smooth workers' operation if necessary. A worker's output depends on the normal operation and functioning of the machine. If a machine breaks down, the worker who operates it calls maintenance staff for repairs and the maintenance staff records the duration of the breakdown. The worker can neither change to a different machine nor leave the site, which means that the worker's production is completely interrupted until the machine is fixed. ${ }^{3}$

Team managers are paid a flat rate, while workers are paid a two-tier piece rate based on their daily output and the specified target level. Specifically, on a typical day and for each product-machine pair, the general production manager specifies a target, denoted by $\bar{Q}_{p m}$, which depends on the features of product $p$ and machine $m$. When they meet the target, workers are paid a piece rate denoted by $\alpha_{1}$ per unit of output. When output exceeds the target, a higher rate, denoted by $\alpha_{2}$ (where $\alpha_{2}>\alpha_{1}$ ), applies to each unit above the target. When a worker fails to meet the benchmark, the unfulfilled units are also

\footnotetext{
${ }^{3}$ Whether the machine is fixed or not by the end of the workday, the next day, the worker always rotates machines and products as any other workers do.
} 
deducted by the rate $\alpha_{2}$. Formally, given the worker's daily production $Q_{i p m d}$, the salary is determined as $\alpha_{1} \bar{Q}_{p m}+\alpha_{2}\left(Q_{i p m d}-\bar{Q}_{p m}\right){ }^{4}$ The target will be proportionally adjusted if machine breakdown occurs to a worker, i.e., given a breakdown of $x$ hours, the new target becomes $\tilde{Q}_{p m}=\bar{Q}_{p m} \frac{12-x}{12}$.

\subsection{A Stylized Model}

We construct a parsimonious and stylized model to illustrate our research setting. Consider that the company has $N$ workers indexed by $i, P$ products indexed by $p$, and $M$ machines indexed by $m$. The production function is denoted as $Q_{i p m d}=Q\left(e_{i d}, x_{i p m d}\right)$, where $e_{i d}$ is the effort chosen by worker $i$ on day $d$; and $x_{i p m d}$ are exogenous variables that affect daily output, such as worker proficiency, product features, machine conditions, weather and pollution, etc. $Q($.$) has the features of a standard production function, i.e., Q_{e}>0, Q_{e e}<0, Q_{x}>0$, and $Q_{e x}>0$.

The effort exerted by the workers is assumed to have the following cost function, $C_{i d}=$ $C\left(e_{i d}, w_{i d}\right)$, where $w_{i d}$ are external factors such as the mental status of the worker, and the regular assumptions for a cost function apply, namely, $C_{e}>0, C_{e e}>0, C_{w}<0$, and $C_{e w}<0$.

Hence, the optimal effort chosen by worker $i$ on day $d$ is given by

$$
\begin{gathered}
\max _{e_{i d}} Q\left(e_{i d}, x_{i p m d}\right)-C\left(e_{i d}, w_{i d}\right) \\
\Rightarrow e_{i d}^{*}=e\left(x_{i p m d}, w_{i d}\right)
\end{gathered}
$$

Linking the optimal output $Q_{i p m d}^{*}$ to the external variables $\left(x_{i p m d}\right.$ and $\left.w_{i d}\right)$, we have

$$
\frac{\partial Q_{i p m d}^{*}}{\partial x_{i p m d}}=Q_{e} \frac{\partial e_{i d}^{*}}{\partial x_{i p m d}}+Q_{x}=Q_{e} \frac{Q_{e x}}{C_{e e}-Q_{e e}}+Q_{x}>0,
$$

and

$$
\frac{\partial Q_{i p m d}^{*}}{\partial w_{i d}}=Q_{e} \frac{\partial e_{i d}^{*}}{\partial w_{i d}}=Q_{e} \frac{C_{e w}}{Q_{e e}-C_{e e}}>0
$$

Next, we use equations (1) and (2) to illustrate the effect of machine breakdown on day $d-1$ on output on day $d$, and the potential bias from omitted variables. We also extend the framework to incorporate heterogenous effects across workers.

Effect of Machine Breakdown on Day $d-1$. Machine breakdown on day $d-1$ may

\footnotetext{
${ }^{4}$ In principle, the daily salary could be negative if output level is very low, i.e., $Q_{i p m d}<\frac{\alpha_{2}-\alpha_{1}}{\alpha_{2}} \bar{Q}_{p m}$. However, there is no such case in our data, presumably the specified target output level $\bar{Q}_{p m}$ is at a reasonable level and workers exert sufficient efforts.
} 
affect the output $Q_{i p m d}^{*}$ on day $d$ through production factor $x_{i p m d}$, or cost factor $w_{i d}$, or both. Consider first the possibility that breakdown affects $x_{i p m d}$. For example, after a substantially long interruption, workers may become less proficient and less engaged in the task, and need to start over with the techniques and procedures (Jett and George, 2003). In our context, it is possible that workers take time to configure and tune their machines, prepare relevant materials and work logs, and adjust the pace according to their own and their peers' productivity. The process of reaching maximum proficiency imposes a fixed cost on productivity; once it is interrupted, workers have to start over again and incur such a cost. Formally, let $B_{i m^{\prime} p^{\prime} d-1}$ denote whether machine $m^{\prime}$ used for product $p^{\prime}$ on day $d-1$ is broken. ${ }^{5}$ The proficiency effect means that $\frac{\partial x_{i p m d}}{\partial B_{i m^{\prime} p^{\prime} d-1}}<0$, which causes $\frac{\partial Q_{i p m d}^{*}}{\partial B_{i m^{\prime} p^{\prime} d-1}}<0$. However, occasional breaks due to interruptions may alleviate fatigue and promote workers' subsequent productivity (Roy, 1959), or may induce income targeting behavior across days (Camerer et al., 1997), in which cases we would have the reverse, namely, $\frac{\partial x_{i p m d}}{\partial B_{i m^{\prime} p^{\prime} d-1}}>0$, leading to $\frac{\partial Q_{i p m d}^{*}}{\partial B_{i m^{\prime} p^{\prime} d-1}}>0$.

The other possibility is that machine breakdown affects the external factor of workers' cost of effort $w_{i d}$. For example, workers may feel frustrated by machine breakdown, either because it is unpleasant, goes against their expectation of the production process, or they are disappointed by the fact that their daily salary will be compromised due to the lost hours. The negative emotions and reactions make hardworking more costly, or, $\frac{\partial w_{i d}}{\partial B_{i m^{\prime} p^{\prime} d-1}}<0$, which causes $\frac{\partial Q_{i p m d}^{*}}{\partial B_{i m^{\prime} p^{\prime} d-1}}<0$.

Omitted Variables Bias. - Despite the fact that rotation of workers to machine and product is done at a daily basis, one may still be concerned that there are other factors associated or even causing machine breakdown in day $d-1$, and they persist to affect either the efficiency of production in day $d$ through $x_{i p m d}$, or the cost of effort through $w_{i d}$, or both, which in turn changes the output level $Q_{i p m d}^{*}$. Specifically, we consider two possible scenarios - the manipulation of production assignment by team managers and the manipulation of machine conditions by workers, and conduct several robustness checks on these concerns. We discuss this identification issue in details in the next section.

Heterogeneous Effects. - Thus far, we have considered an average effect across all the workers; that is, workers have the same production function $Q($.$) as well as cost function$ $C($.$) . However, worker heterogeneity may generate different output and cost functions, i.e.,$ $Q_{g}($.$) and C_{g}($.$) , where g$ indexes the worker type and hence potentially heterogeneous effects

\footnotetext{
${ }^{5}$ We use different notation for machine and product on day $d$ and day $d-1$ because workers rotate jobs and machines each day.
} 
from machine breakdown. In the further analyses, we consider several possible heterogeneous effects across workers - specifically, gender, age, and local versus migrant workers.

\section{Estimation Strategy}

\subsection{Data, Variables, and Specification}

Our data contain worker output and machine conditions for each workday from October 2012 to April 2014. The sample has a total of 24,081 obervations, covering 473 workdays, 273 workers, 75 machines and 25 product categories. ${ }^{6}$ We estimate the effect of machine breakdown on a worker's subsequent productivity by comparing productivity with and without machine breakdown one day before. Specifically, we model our estimation framework as follows:

$$
y_{i m p d}=\beta * B_{i m^{\prime} p^{\prime} d-1}+\lambda_{i}+\lambda_{p d}+\lambda_{p m}+\mathbf{X}_{i m\left(m^{\prime}\right) p\left(p^{\prime}\right) d(d-1)}^{\prime} \boldsymbol{\eta}+\varepsilon_{i m p d} .
$$

where $i$ indicates worker; $d$ indicates day; $m\left(m^{\prime}\right)$ and $p\left(p^{\prime}\right)$ indicate machine and product for $d(d-1)$, respectively. We cluster the standard errors at the worker level to control for any heteroskedasticity and serial correlation (Bertrand, Duflo and Mullainathan 2004).

To account for variations in machine efficiency across days and product types, we define worker productivity $y_{i m p d}$ as over-target percentage of output; specifically, $y_{i m p d} \equiv$ $\left(Q_{i m p d}-\bar{Q}_{p m}\right) / \bar{Q}_{p m}$. As workers' compensations are completely based on their daily outputs, both the firm and workers make effort to record productivity precisely, suggesting minimal measurement errors.

The regressor of interest $B_{i m^{\prime} p^{\prime} d-1}$ is a dummy variable, indicating whether on day $d-1$, worker $i$ 's machine was broken down. Note that as a worker rotates product and machine on a daily basis, the worker may not work on the same machine on two consecutive days. In other words, the machine used by a worker on day $d-1$ may not be the same machine the worker operated on day $d$, i.e., $m^{\prime} \neq m$. Similarly, it is possible that workers are assigned to different products across two days, i.e., $p^{\prime} \neq p$.

We plot the number of machine breakdowns each workday during our observation period in Figure 1. Machine breakdown happened frequently: the average frequency was about 14 percent and fluctuated a lot across days, ranging from 0 percent to 100 percent (see Figure 2 for the density distribution of daily percentage of machine breakdown). ${ }^{7}$ In Appendix Table

\footnotetext{
${ }^{6}$ For regression analyses, the sample size drops to 20,157 as it requires two consecutive observations for the same worker. We further check and rule out concerns about sample selection - that is, machine breakdown on day $d-1$ causes worker absence on day $d$ (see Appendix Table A1, column 1).

${ }^{7}$ There was one day when all machines (12 machines) were broken. To address the concern that our estimates may be driven by this abnormal workday, we exclude it from the analysis and find similar results
} 
A2, we further link the percentage of machines that broke down to various workday characteristics, such as the day of the week, the month of the year, temperature, precipitation, wind speed, and air pressure. Machine breakdown is more prevalent when it is hot and sunny; with higher air pressure; on Mondays, Tuesdays and Wednesdays (less on Saturdays); and varies across months. To control for these daily variations, we include product-day fixed effects $\lambda_{p d}$, and hence, our identification comes from the comparison across workers producing the same product on the same day, with versus without machine breakdown the day before.

[Insert Figure 1 here]

[Insert Figure 2 here]

We further control for confounders through a battery of fixed effects. In addition to product-day fixed effects $\lambda_{p d}$, we also include: (1) worker fixed effects $\lambda_{i}$, to control for all time-invariant worker characteristics; and (2) product-machine fixed effects $\lambda_{p m}$, to address the concern that a machine's efficiency highly depends on the features of the product.

To improve our identification further, we add additional variables, $\mathbf{X}_{i m\left(m^{\prime}\right) p\left(p^{\prime}\right) d(d-1)}$, to control for various cross-day spillovers. Specifically, to control for any overnight exhaustion, we include worker $i$ 's productivity on day $d-1$. To control for cross-day spillovers from the product, we include the average productivity of all other workers producing $p^{\prime}$ on day $d-1$ (same as the concerned worker $i$ ). To account for machine $m$ 's usage and condition on day $d-1$, we control for its over-target percent of productivity and whether it was broken down on day $d-1$. We also include a dummy variable indicating whether the worker was operating the same machine as the day before, i.e., whether $m=m^{\prime}$, to control for cross-day spillovers from the worker-machine pair. Finally, we include worker $i$ 's working hours on day $d$ to control for any intraday exhaustion or proficiency effects.

\subsection{Identifying Assumption and Validity Checks}

The identifying assumption of equation (3) requires that machine breakdown is exogenous to the individual worker, conditional on the controls $\left(\lambda_{i}, \lambda_{p d}, \lambda_{p m}\right.$, and $\left.\mathbf{X}_{i m\left(m^{\prime}\right) p\left(p^{\prime}\right) d(d-1)}\right)$. As described in Section 2.1, for fairness of compensation, workers rotate jobs on a daily basis so that an individual is not attached to a particular machine or product. In Figure 3, we plot the distribution of the number of machines a worker operated throughout our sample period. Workers on average have operated 8.68 different machines; four workers have used (see Appendix Table A1, column 2). 
more than 30 machines. In sum, the daily rotation of team, product, and machine provides randomness of machine breakdown for a worker on a given day.

\section{[Insert Figure 3 here]}

However, there may be other concerns about our identifying assumption. The primary threat to our identification is that machine breakdown on day $d-1$ was manipulated and the factors of manipulation continued to influence production on day $d$. Two primary possibities are manipulation by team managers and manipulation by workers. In the following, we first discuss these two scenarios and remedies, and then take a closer look at the omitted variables bias in our estimation.

Manipulation by Team Managers. - Our estimates would be biased if the assignment of workers to machines was manipulated by team managers based on worker productivity and machine quality. However, several features of our research setting provide confidence to dispel this concern and validate our identifying assumption.

First, as team managers are paid a flat rate instead of by performance, they are not fully incentivized to exert effort to match workers and machines optimally for productivity, e.g., by assigning more productive workers to better-maintained machines. ${ }^{8}$ In our regression analysis, the inclusion of worker fixed effects further removes any favoritism by team managers based on social connections, such as favoring workers from the same origins or networks. Second, teams are formed on-site each morning and, therefore, across days a given worker is likely to be supervised and assigned to machines by different team managers. ${ }^{9}$ Hence, bias from manipulation would require that all team managers have similar preferences on matching certain workers to better machines.

Finally and most importantly, even if team managers assign workers based on machine and/or worker characteristics, machine breakdown is probabilistic and cannot be fully manipulated. For a given workday, neither the team manager nor the worker knows with certainty whether or not the machine is going to break down - even if some machines are in worse condition than others. In other words, whether machine $m^{\prime}$ would break down on day $d-1$, $B_{m^{\prime} d-1}$, is a function of two components: a systematic, predictable component $\left(c_{m^{\prime} d-1}\right)$ related to machine condition (e.g., past breakdown history) and observable to team managers, and an exogenous, random element $\left(v_{m^{\prime} d-1}\right)$ of chance (e.g., whether the workshop has the

\footnotetext{
${ }^{8}$ Bandiera et al. (2009) examine how managerial incentive schemes affect the allocation of workers to tasks. They find that when managers are paid performance bonuses, they exert more effort helping high-ability workers; when managers are paid fixed wages, they favor workers with whom they are socially connected.

${ }^{9}$ Unfornately, our data do not contain information on team formation, which precludes us from directly checking the matching between workers and team managers.
} 
"wrong" temperature and humidity that day, or the raw material has defects that damage the machine), i.e., $B_{m^{\prime} d-1}=g\left(c_{m^{\prime} d-1}\right)+v_{m^{\prime} d-1}$. As long as $v_{m^{\prime} d-1} \neq 0$, machine breakdown is arguably random even in the presence of endogenous assignment (i.e., $c_{m^{\prime} d-1} \neq 0$ ). This argument is similar to the without-full-manipulation argument underpinning regression discontinuity design as elaborated by Lee (2008). Also motivated by the literature on regression discontinuity design (Lee and Lemieux 2010), we control for $g(c)$ in the regression to isolate the randomness of machine breakdown. Specifically, we proxy machine condition $c$ using the historical frequency of machine breakdown (i.e., in the past five days) ${ }^{10}$ and proxy $g($.$) using$ a second-order polynomial function with varying coefficients for scenarios with and without machine breakdown. ${ }^{11}$

Manipulation by Workers.-Our results would also be biased if there were manipulation by workers. For example, if a worker experiences a negative shock (e.g., sickness) on day $d-1$, the worker may mishandle the machine, leading it to break down. If the negative shock persists to day $d$, the worker's productivity would be negatively affected too, generating a spurious correlation between the machine breakdown on day $d-1$ and decreased productivity on day $d$. We address this concern with institutional knowledge as well as formal quantitative tests.

First, workers are paid by their output (piece-rate) and therefore have no incentive to sabotage intentionally. Moreover, the company has implicit policies against deliberate machine sabotage, which is costly in repair expenditure and output losses. Team managers patrol from machine to machine to make sure that the machines are being properly operated. Hence, workers are unlikely to dramatically change how they operate machines just because of some external shocks, but possibly exert less effort or become careless in maintaining machines. These behaviors may increase the probability of machine breakdown but not in a deterministic way, and it is the uncertainty that validates our identification even with the presence of some worker manipulation.

To check further whether our estimates may be biased due to worker manipulation, we conduct a quantitative analysis based on the following premise. If our results were mostly driven by worker manipulation (causing both machine breakdown on day $d-1$ and low productivity on day $d$ ), the effects should not vary substantially by the duration of the resultant interruption, i.e., work interrupted for a short versus long period. As an interruption hinges on the condition of the machine and the efforts of the maintenance staff, the affected

\footnotetext{
${ }^{10}$ Results using the historical frequency of machine breakdown in the past 3 days and 7 days are similar (see Appendix Table A1, columns 3 and 4).

${ }^{11}$ Gelman and Imbens (2014) suggest the use of the second-order polynomial function in the regression discontinuity analysis, and we follow their advice here.
} 
workers cannot fully control the duration of interruption. Given that there are substantial variations in the average length of interruption across days and across incidents, ${ }^{12}$ we divide our regressor of interest $B_{i m^{\prime} p^{\prime} d-1}$ into two, $B_{i m^{\prime} p^{\prime} d-1}^{a b v e}$ (a dummy variable indicating breakdown duration above sample mean) and $B_{i m^{\prime} p^{\prime} d-1}^{\text {below }}$ (a dummy variable indicating breakdown duration below sample mean), and check whether the effect of machine breakdown on the worker's subsequent productivity varies by the duration of the interruption. If there were omitted variables bias due to worker manipulation, we should expect similar effects between short and long periods of interruption.

A Further Look and Placebo Tests. - Here we take a closer look at the omitted variables bias. Specifically, let $\varepsilon_{i m p d}=\gamma \omega_{i m p d}+\tilde{\varepsilon}_{i m p d}$, such that $\operatorname{cov}\left(B_{i m^{\prime} p^{\prime} d-1}, \omega_{i m p d} \mid \mathbf{W}_{i m\left(m^{\prime}\right) p\left(p^{\prime}\right) d(d-1)}\right) \neq$ 0 and $\operatorname{cov}\left(B_{i m^{\prime} p^{\prime} d-1}, \tilde{\varepsilon}_{i m p d} \mid \mathbf{W}_{i m\left(m^{\prime}\right) p\left(p^{\prime}\right) d(d-1)}\right)=0$, where $\mathbf{W}_{i m\left(m^{\prime}\right) p\left(p^{\prime}\right) d(d-1)}$ summarizes all the controls in the regressions $\left(\lambda_{i}, \lambda_{p d}, \lambda_{p m}, \mathbf{X}_{i m\left(m^{\prime}\right) p\left(p^{\prime}\right) d(d-1)}^{\prime}\right)$. In other words, all the potential omitted variables bias comes from $\omega_{\text {impd }}$. Hence, our estimator $\hat{\beta}$ is

$$
\hat{\beta}=\beta+\gamma \delta
$$

where $\delta \equiv \frac{\operatorname{cov}\left(B_{i m^{\prime} p^{\prime} d-1}, \omega_{i m p d} \mid \mathbf{W}_{i m\left(m^{\prime}\right) p\left(p^{\prime}\right) d(d-1)}\right)}{\operatorname{var}\left(B_{i m^{\prime} p^{\prime} d-1} \mid \mathbf{W}_{i m\left(m^{\prime}\right) p\left(p^{\prime}\right) d(d-1)}\right)}$. And $\hat{\beta} \neq \beta$ if $\gamma \delta \neq 0$.

We have discussed two potential sources of $\omega_{i m p d}$, manipulation by team managers and manipulation by workers. To check further whether there is still $\omega_{\text {impd }}$ after controlling for manipulation, we conduct two placebo tests. The premise is to replace the regressor of interest $B_{i m^{\prime} p^{\prime} d-1}$ with other regressors that conceptually do not have any effect on worker productivity on day $d$. If there are no omitted variables in our specification (3), i.e., $\gamma=0$, we shall find $\tilde{\beta}=0$ from these placebo tests.

In the first placebo test, we replace $B_{i m^{\prime} p^{\prime} d-1}$ with a dummy variable $B_{i m^{\prime} p^{\prime} d-1}^{\text {other }}$ indicating whether worker $i$ 's counterpart on the other shift, who also operates machine $m$ on day $d$, experienced machine breakdown on day $d-1$. Unless the two workers were attached to the same machine for two consecutive days, $B_{i m^{\prime} p^{\prime} d-1}^{o t h}$ should have no effects on worker $i$ 's performance on day $d$ (i.e., $\beta^{\text {other }}=0$ ), as the two workers had different trajectories. Hence, if $\gamma=0$, we shall have $\hat{\beta}^{\text {other }}=0$.

In our second placebo test, we randomly assign machine breakdown to workers. Specifically, during our sample period, there are 24,081 observations and 3,466 incidents of machine breakdown. We randomly distribute these 3,466 incidents to the 24,081 observations, and generate a false machine breakdown variable, $B_{i m^{\prime} p^{\prime} d-1}^{\text {false }}$. The randomization ensures that

\footnotetext{
${ }^{12}$ Appendix Figure A1 plots the distribution of the duration of interruption for each day. Appendix Figure A2 plots the distribution of the duration of each incident, which ranges from 0.2 to 11.8 hours and has a mean of 4 hours.
} 
$B_{i m^{\prime} p^{\prime} d-1}^{\text {false }}$ should have no effect on worker $i$ 's performance on day $d$ (i.e., $\beta^{\text {false }}=0$ ); hence, if $\gamma=0$, we have $\hat{\beta}^{\text {false }}=0$. We conduct this random data generating process 500 times to avoid contamination by any rare events (e.g., $\beta^{\text {false }} \neq 0$ ).

\section{Empirical Findings}

Table 1 reports the regression results of specification (3). In column 1, we only include three sets of fixed effects - the worker fixed effect, the product-day fixed effect, and the product-machine fixed effect - and find that the coefficient of interest, $B_{i m^{\prime} p^{\prime} d-1}$, is negative and statistically significant. In column 2 , we add a series of machine, worker and product characteristics to control further for any potential estimation biases caused by exhaustion and cross-day spill-overs. We find that the effect remains negative and significant, in spite of a slight decline in the magnitude.

\section{[Insert Table 1 here]}

In the rest of this section, we report results from several validity checks, estimate the economic magnitude, examine two possible interpretations, and finally explore the heterogeneous effects.

\subsection{Validity Checks}

In this subsection, adopting the methods detailed in Section 3.2, we report the results from several validity checks on our identifying assumption in equation (3).

Check on Potential Manipulation by Team Managers. - If the team managers manipulate the assignment of workers to machines based on machine quality, our estimates would be biased. To isolate the effect from the potential manipulation by team managers, we further control for machine condition that are observable by team managers. We proxy machine condition using the machine's breakdown frequency in the past five days, and include a flexible second-order polynomial function of the frequency in the regression analysis. The results are robust and the magnitude slightly increases, as reported in column 3 of Table 1.

Check on Potential Manipulation by Workers. - If workers could manipulate the machine conditions, the estimates could also be biased. For example, some unobservables, such as illness or family issues, led the workers to mishandle the machine on the first day as well as to reduce effort on the second day. If our results were mostly driven by worker manipulation, the effects in principle should not vary substantially by the duration of the interruption 
as workers have little control over the duration of machine breakdown. Building on this assumption, we divide $B_{i m^{\prime} p^{\prime} d-1}$ into two, $B_{i m^{\prime} p^{\prime} d-1}^{a b o v e}$ and $B_{i m^{\prime} p^{\prime} d-1}^{\text {below }}$, based on whether the duration of machine breakdown is above or below the sample mean, and examine whether $B_{i m^{\prime} p^{\prime} d-1}^{a b o v e}$ would obtain a higher estimate than $B_{i m^{\prime} p^{\prime} d-1}^{\text {below }}$. Indeed, the results in column 4 of Table 1 show that this is the case in our setting, implying no significant manipulation by workers.

Placebo tests.- As further checks on our identifying assumption to ensure that our estimates are unlikely to be caused by omitted variables, we conduct two placebo tests as proposed in Section 3.2. In the first test, we replace $B_{i m^{\prime} p^{\prime} d-1}$ with $B_{i m^{\prime} p^{\prime} d-1}^{o \text { (indicating }}$ whether worker $i$ 's counterpart from the other shift - who used the same machine as the concerned worker on day $d$-experienced machine breakdown on day $d-1$ ). As shown in column 5 of Table 1 , the coefficient of $B_{i m^{\prime} p^{\prime} d-1}^{\text {other }}$ is insignificant and small in magnitude, suggesting that there are no omitted variables in our specification.

For the second placebo test, we randomly assign machine breakdown and repeat 500 times. Figure 4 shows the distribution of estimates from the 500 times of randomization and our benchmark estimate, -0.024 , from column 3 of Table 1 . We find that the distribution of estimates from random assignments is centered around zero (the mean value is 0.000034 ), and the standard deviation of the estimates is 0.0042 , suggesting that $\hat{\beta}^{\text {false }}=0$. In addition, our benchmark estimate clearly lies outside the estimates from the placebo tests. Altogether, these results imply that there are no substantial omitted variables in our specification.

[Insert Figure 4 here]

In sum, from all the aforementioned checks, we cannot reject the hypothesis that our estimation is well specified and the identifying assumption is satisfied.

\subsection{Economic Magnitude}

To calculate the economic magnitude of the effect of machine breakdown on subsequent productivity, we use the estimate from column 3 of Table 1: if a worker experiences machine breakdown on day $d-1$, the worker's over-target percentage of output on day $d$ would fall by 2.4 percentage points. Given that the control group - workers without machine breakdown on day $d-1$ - has an average of 17.5 percent over-target of output on day $d$, machine breakdown reduces workers' over-target percent of productivity by $2.4 / 17.5=13.7$ percent, or gross daily output by $2.4 / 117.5=2.04$ percent.

We further investigate how long this negative effect persists by including dummies indicating machine breakdown on day $d-2$ and on day $d-3$. The results are reported in 
column 6 of Table 1. We find that the effect drops by around 50 percent by the third day (with an estimated coefficient of -0.011) and seems to persist even by the fourth day (with an estimated coefficient of -0.014). This adds strength to our observation and suggests that the negative spill-overs could last for days.

\subsection{Interpretation}

We establish that work interruption from machine breakdown casts a negative and significant effect on workers' productivity the following day. As elaborated in Section 2.2, this effect may come from the influence on production $\left(x_{i p m d}\right)$, or the cost of effort $\left(w_{i d}\right)$, or both. In this subsection, we discuss and test two possible channels, that is, from the view of production proficiency and workers' emotional reactions towards interruption.

Proficiency. - It is possible that after an interruption of substantial length, workers may become less proficient and need to warm up with techniques and procedures. Formally, we assume that production proficiency $x_{i p m d}$ is a function of cumulated working hours until day $d$, i.e., $x_{i p m d}=f\left(H_{j d-1}\right)$, where $f^{\prime}>0, H_{i d-1} \equiv \sum_{j=1}^{d-1} h_{i j}$, and $h_{i j}$ is the number of hours worked on day $j$. Machine breakdown reduces the cumulated hours and therefore lowers production proficiency, i.e., $\frac{\partial H_{i d-1}}{\partial B_{i m^{\prime} p^{\prime} d-1}}<0 \Rightarrow \frac{\partial x_{i p m d}}{\partial B_{i m^{\prime} p^{\prime} d-1}}<0$. We have $\frac{\partial^{2} x_{i p m d}}{\partial B_{i m^{\prime} p^{\prime} d-1} \partial H_{i d-2}}<0$, if $f^{\prime \prime}>0$. In other words, when proficiency has increasing returns to experience (accumulated hours), productivity loss from interruption is larger for a more intensive work schedule (i.e., larger $\left.H_{i d-2}\right)$.

To provide quantitative support to this potential channel, we investigate whether the effect of machine breakdown on day $d-1$ is different for workers present or absent from work on day $d-2 .{ }^{13}$ More specifically, the proficiency hypothesis would predict that the effect would be larger when the workers are present on day $d-2$, compared with when they are absent. Regression results are reported in column 1 of Table 2. Consistent with the our hypothesis, the estimated effect of interruption is larger when the worker was present on day $d-2$, i.e., when machine breakdown occured during a more intensive working period.

\section{[Insert Table 2 here]}

Emotional Reaction. - Machine breakdown may also cause emotional reactions (like frustration, disappointment, etc.), which may raise the marginal cost of effort $w_{i d}$ and hence reduce output on day $d$. For example, Ockenfels et al. (2014) show that when bonus pay-

\footnotetext{
${ }^{13}$ To address the concern that absence on day $d-2$ may have been caused by negative external shocks, such as illness (which may persist to affect activities on day $d-1$ and on day $d$ ), we focus on relatively long leaves (i.e., absence on day $d-2$ was not the first day of leave).
} 
ments fall short of individually assigned bonus targets, workers are disappointed, leading to lower work satisfaction and performance. Mas (2006) finds that after New Jersey police officers lose in final-offer arbitration over salary demands, relative to when they win, arrest rates and average sentence length decline and crime reports rise. Oswald et al. (2014) show that increased happiness leads to higher productivity, and decreased happiness caused by major real-world shocks, including bereavement and family illness, leads to lower productivity. These results are consistent with a causal link between workers' subjective well-being and productivity. ${ }^{14}$

To check this potential channel, we investigate whether the effect depends on the worker's experience, i.e., whether it was the first machine breakdown for the worker. Intuitively, if the effect is due to emotional reaction, we might expect to observe a larger effect when the workers experience breakdown for the first time. Regression results are reported in column 2 of Table 2. We find that the first incident of machine breakdown has a larger effect (around 50 percent larger, albeit not statistically significant) than subsequent incidents. Considering that the emotional response is stronger for the first experience of machine breakdown, these findings support the channel that interruption lowers productivity through emotions.

To sum, these results could not reject either of the two explanations. These findings suggest that production proficiency and emotional reactions may have jointly contributed to the observed negative effect of machine breakdown in our setting.

\subsection{Additional Results: Heterogeneity and Social Comparison}

We now explore the heterogeneous effects across worker characteristics, as it has been suggested that there is substantial heterogeinity in economic behavior, which is partially accounted by demorgraphic information. Dohmen et al. (2011) conduct a study with a representative sample of roughly 22,000 individuals in Germany, and find that willingness to take risks is negatively related to age and to being female, and positively related to height and parental education. Moreover, it has been suggested that gender plays an important role in economic preference (Croson and Gneezy 2009), and elderly individuals are less biased than younger individuals for some decision behaviors (Kovalchik et al. (2005)). Motivated by these studies, we examine whether the effect of machine breakdown differs by workers' gender, age, and place of residence.

\footnotetext{
${ }^{14}$ Relatedly, a negative shock at a workplace may induce angry and even harmful behaviors by the workere.g., drinking, violence, or deliberate sabotage - which, in turn, lowers their second-day productivity. Card and Dahl (2011) observe that losses in professional football matches increase the rate of at-home violence by men against their wives or girlfriends. Loewenstein (2000) suggests that emotions, including a wide range of visceral factors, underpin daily economic behavior. For example, angry negotiators could become obsessed with causing harm to the other party, even at the cost of harming themselves.
} 
Columns 1-3 of Table 3 report the results. In each column, we identify the heterogeneity by including the interaction of worker characteristics and the breakdown dummy. We find the effect does not differ by workers' age. There seems to be some heterogeneity by gender and place of residence: the negative effect is larger among male workers than female workers, and is also larger among migrant workers than local workers, albeit the estimates are imprecisely identified.

\section{[Insert Table 3 here]}

Finally we check whether the effect is reinforced or mitigated by social comparison. For example, a worker may feel much worse if she is the only worker experiencing machine breakdown on day $d-1$, leading to an enlarged effect on reduction in productivity on day $d$. Social comparison in the workplace has been extensively explored in the literature. Mas and Moretti (2009) observe that a 10 percent increase in co-worker productivity is associated with a 1.5 percent increase in a worker's productivity, indicating that workers are motivated by social pressure and mutual monitoring. De Grip and Sauermann (2012) exploit a field experiment and observe that a 10 percentage points increase in the share of treated peers improves an individual's performance by 0.51 percent. Guryan et al. (2009) make use of random assignment in professional golf tournaments to test for peer effects and find no evidence that playing partners' ability affects performance.

To fit our setting, we include the percentage of machines that broke down on day $d-1$ as well as its interaction with the breakdown dummy. Column 4 of Table 3 presents the results. The coefficient is positive yet insignificant, providing weak evidence suggesting that when there are fewer peers facing interruption, the negative effect on a worker's productivity tends to be larger. Our results provide support to existing literature on social comparison in the workplace.

\section{Conclusion}

This paper investigates how work interruption arising from machine breakdown affects workers' subsequent productivity. Using daily output data, we show that individual productivity declines following a workday with machine breakdown. The result is robust after controlling for various characteristics of the machine and the worker and a battery of fixed effects, as well as after addressing concerns including manipulation of production assignment by team managers and manipulation of machine breakdown by the workers. Our findings imply a hidden cost of work interruption: the cost is not limited to the lost hours and productivity 
during the interruption, but may spill over to subsequent production and last for days.

Our findings have direct implications for the cost-benefit analysis of managing production. The hidden but economically significant cost is relevant to the decision of whether and how much resources to spend in managing interruptions, including maintaining equipment and arranging for standbys. A further implication lies in the remedies for interruptions. We discussed two relevant channels through which interruption reduces cross-day productivity, i.e., proficiency decline and negative emotions. To minimize negative spillovers, managers may want to keep the affected individuals working instead of letting them "cool down". If workers act passively due to income loss, it might be helpful to compensate workers for work interruption.

More generally, our study points to work interruption as yet another determinant of productivity, which adds to studies on external factors that contribute to individual productivity, such as incentive schemes, peer effects, weather and pollution, etc. It would be of interest to examine the generalizability of the effect estimated in this paper to other types of interruptions, especially for those caused by communication devices and social media, which are increasingly common and have become concerns for the society. Moreover, given the benefit of smoothing operations and the production process, interruption is an external factor that individuals and firms would like to regulate and manage. Thus it would also be worthwhile to study how best to manage interruptions, possibly through planned or fine-scheduled workflow and self-control devices, in the field settings. These represent a fruitful area for future research toward a better understanding of the causes, consequences, and remedies of interruptions in the workplace.

\section{References}

Andersen, Steffen, Alec Brandon, Uri Gneezy, and John A List, "Toward an Understanding of Reference-Dependent Labor Supply: Theory and Evidence from a Field Experiment," Technical Report, National Bureau of Economic Research 2014.

Bandiera, Oriana, Iwan Barankay, and Imran Rasul, "Social connections and incentives in the workplace: Evidence from personnel data," Econometrica, 2009, 77 (4), 1047-1094.

Bertrand, Marianne, Esther Duflo, and Sendhil Mullainathan, "How Much Should We Trust Differences-In-Differences Estimates?," The Quarterly Journal of Economics, 2004, 119 (1), 249-275. 
Camerer, Colin, Linda Babcock, George Loewenstein, and Richard Thaler, "Labor supply of New York City cabdrivers: One day at a time," The Quarterly Journal of Economics, 1997, pp. 407-441.

Card, David and Gordon B Dahl, "Family violence and football: The effect of unexpected emotional cues on violent behavior," The Quarterly Journal of Economics, 2011, $126(1), 103$.

Connolly, Marie, "Here comes the rain again: Weather and the intertemporal substitution of leisure," Journal of Labor Economics, 2008, 26 (1), 73-100.

Crawford, Vincent P and Juanjuan Meng, "New York City Cab Drivers' Labor Supply Revisited: Reference-Dependent Preferences with Rational-Expectations Targets for Hours and Income," The American Economic Review, 2011, pp. 1912-1932.

Croson, Rachel and Uri Gneezy, "Gender differences in preferences," Journal of Economic literature, 2009, pp. 448-474.

Dohmen, Thomas, Armin Falk, David Huffman, Uwe Sunde, Jürgen Schupp, and Gert G Wagner, "Individual risk attitudes: Measurement, determinants, and behavioral consequences," Journal of the European Economic Association, 2011, 9 (3), 522-550.

Farber, Henry S, "Is Tomorrow Another Day? The Labor Supply of New York City Cabdrivers," Journal of Political Economy, 2005, 113 (1).

_, "Reference-dependent preferences and labor supply: The case of New York City taxi drivers," The American Economic Review, 2008, 98 (3), 1069-1082.

Fehr, Ernst and Lorenz Goette, "Do Workers Work More if Wages Are High? Evidence from a Randomized Field Experiment," The American Economic Review, 2007, pp. 298317.

Gelman, Andrew and Guido Imbens, "Why High-order Polynomials Should not be Used in Regression Discontinuity Designs," Working Paper 20405, National Bureau of Economic Research August 2014.

Grip, Andries De and Jan Sauermann, "The Effects of Training on Own and Coworker Productivity: Evidence from a Field Experiment*," The Economic Journal, 2012, 122 (560), 376-399. 
Guryan, Jonathan, Kory Kroft, and Matthew J Notowidigdo, "Peer Effects in the Workplace: Evidence from Random Groupings in Professional Golf Tournaments," American Economic Journal: Applied Economics, 2009, pp. 34-68.

Herrmann, Mariesa A and Jonah E Rockoff, "Does menstruation explain gender gaps in work absenteeism?," Journal of Human Resources, 2012, 47 (2), 493-508.

_ and _ , "Worker Absence and Productivity: Evidence from Teaching," Journal of Labor Economics, 2012, 30 (4), 749-782.

_ and _, "Do menstrual problems explain gender gaps in absenteeism and earnings?: Evidence from the National Health Interview Survey," Labour Economics, 2013, 24, 1222 .

Ichino, Andrea and Enrico Moretti, "Biological Gender Differences, Absenteeism, and the Earnings Gap," American Economic Journal: Applied Economics, 2009, 1 (1), 183218.

Jett, Quintus R and Jennifer M George, "Work interrupted: A closer look at the role of interruptions in organizational life," Academy of Management Review, 2003, 28 (3), $494-507$.

Kovalchik, Stephanie, Colin F Camerer, David M Grether, Charles R Plott, and John M Allman, "Aging and decision making: A comparison between neurologically healthy elderly and young individuals," Journal of Economic Behavior \& Organization, 2005, 58 (1), 79-94.

Lee, David S, "Randomized experiments from non-random selection in US House elections," Journal of Econometrics, 2008, 142 (2), 675-697.

- and Thomas Lemieux, "Regression Discontinuity Designs in Economics," Journal of Economic Literature, 2010, 48, 281-355.

Loewenstein, George, "Emotions in economic theory and economic behavior," American economic review, 2000, pp. 426-432.

Mandler, George, "Interruption (discrepancy) theory: Review and extensions," On the move: The psychology of change and transition, 1990, 13, 32.

Mas, Alexandre, "Pay, Reference Points, and Police Performance," Quarterly Journal of Economics, 2006, 121 (3). 
- and Enrico Moretti, "Peers at Work," American Economic Review, 2009, 99 (1), 112145 .

Ockenfels, Axel, Dirk Sliwka, and Peter Werner, "Bonus payments and reference point violations," Management Science, 2014.

Oswald, Andrew J, Eugenio Proto, and Daniel Sgroi, "Happiness and Productivity," Journal of Labor Economics, 2014. forthcoming.

Roy, Donald F, "' Banana Time": Job Satisfaction and Informal Interaction," Human organization, 1959, 18 (4), 158-168.

Spira, Jonathan B and Joshua B Feintuch, The cost of not paying attention: How interruptions impact knowledge worker productivity, Basex New York, NY, 2005.

Zivin, Joshua Graff and Matthew Neidell, "The Impact of Pollution on Worker Productivity," The American Economic Review, 2012, 102 (7), 3652-3673.

_ and _ , "Temperature and the allocation of time: Implications for climate change," Journal of Labor Economics, 2014, 32 (1), 1-26. 
Figure 1. Share of Machines that Broke Down (October 2012 - March 2014)

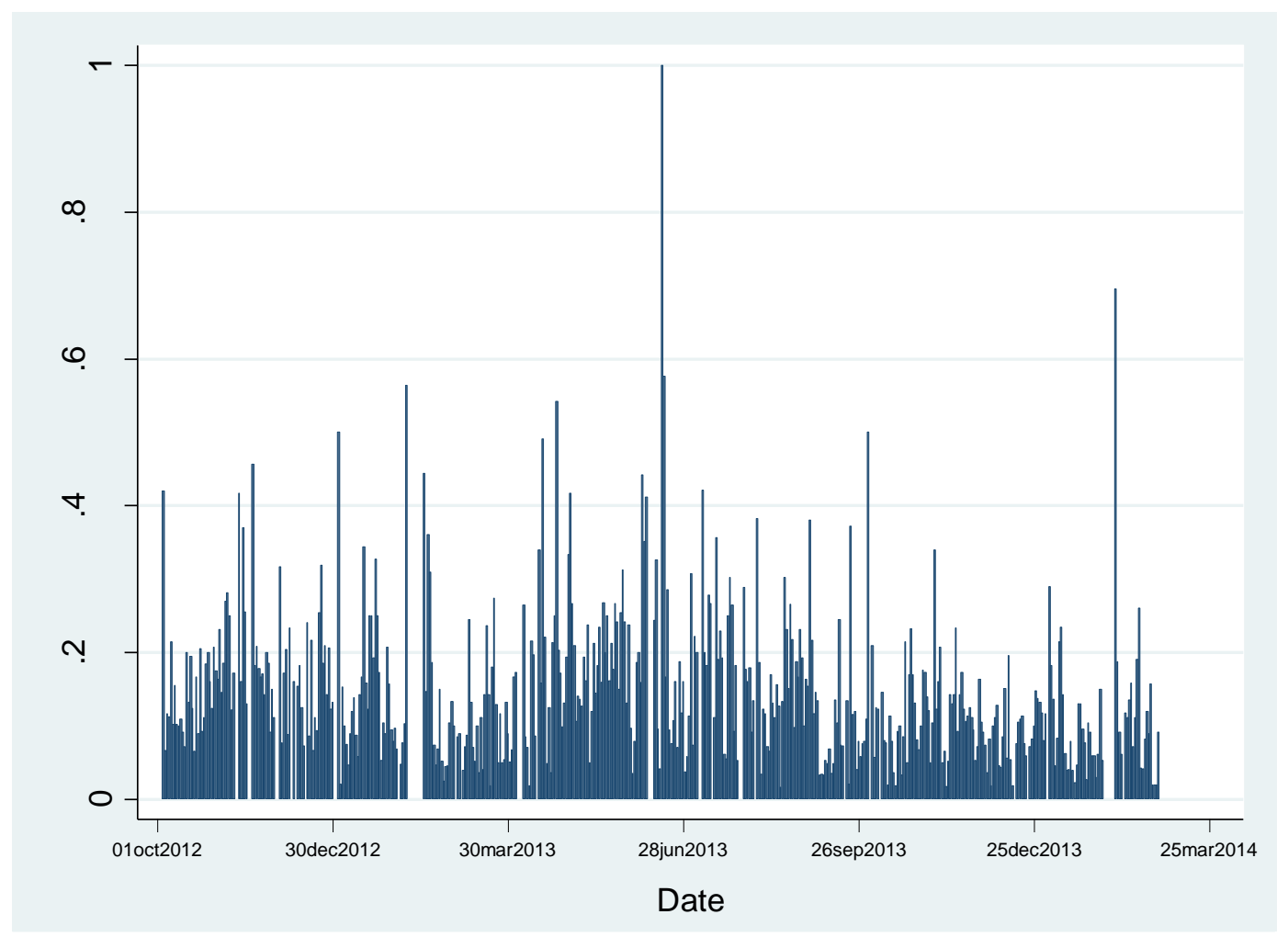

Notes: The figure plots the share of machines that broke down for each workday between October 2012 and March 2014. Vertical axis is the share (between 0 and 1), and the horizontal axis is the date (between October 2012 and March 2014). 
Figure 2: Distribution of Share of Machines that Broke Down

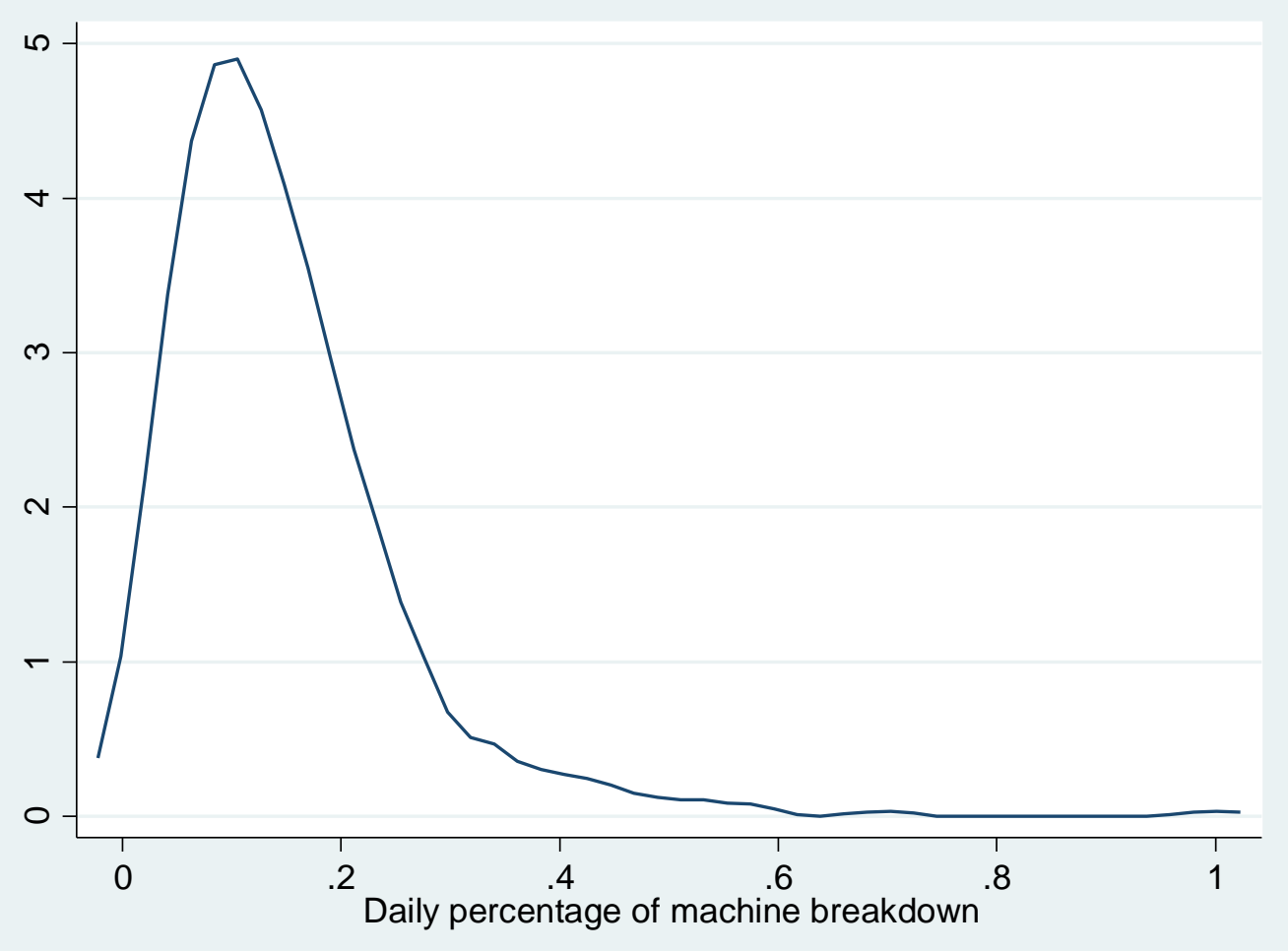

Notes: This figure plots the distribution of share of machines that broke down. The breakdown share is on average around $14 \%$, ranging from $0 \%$ to $100 \%$. 
Figure 3: Distribution of Number of Machines Used by a Worker

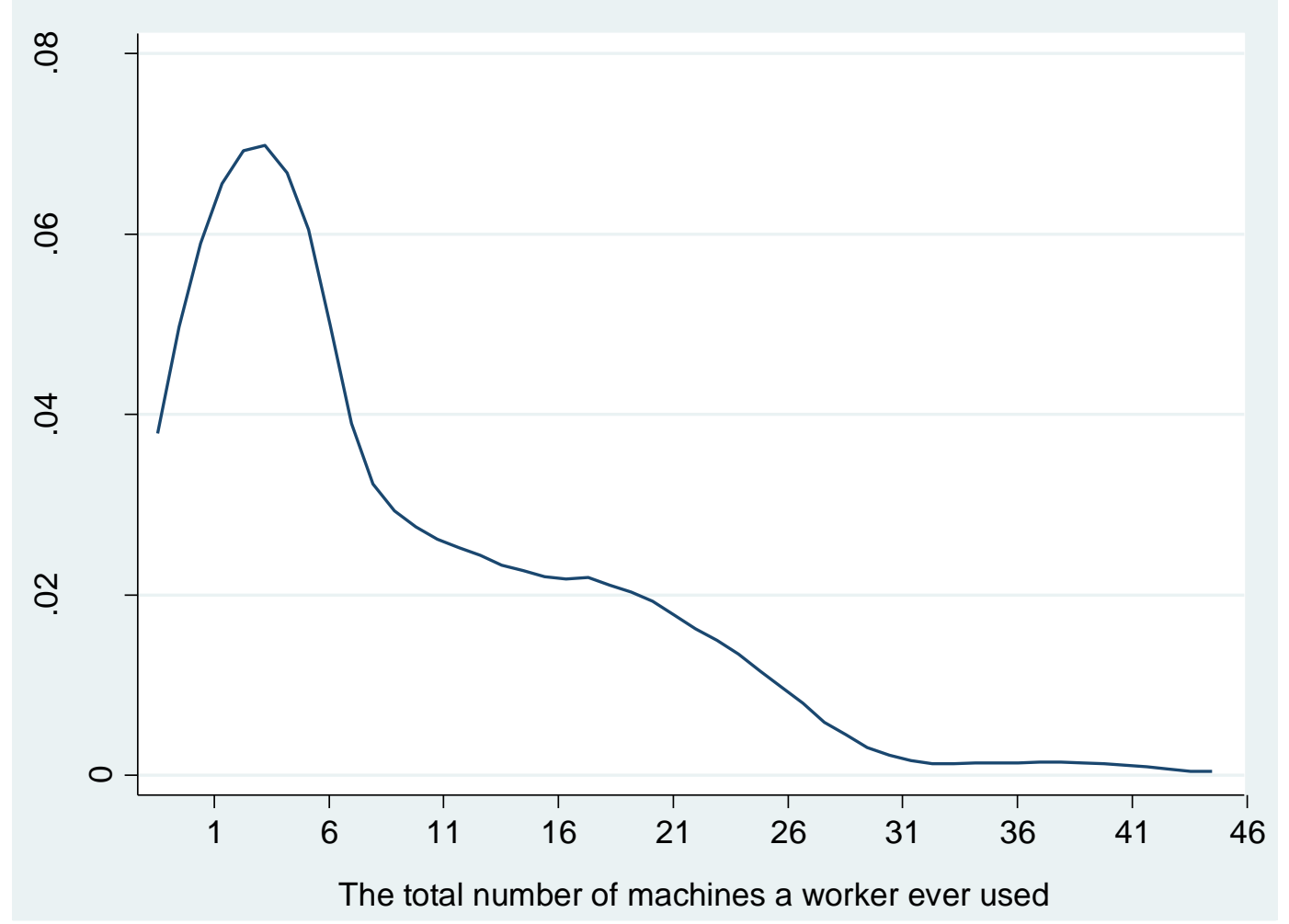

Notes: The figure shows the distribution of the number of machines a worker used in our sample period. 
Figure 4: Placebo: Coefficients from Randomly Distributed Interruptions

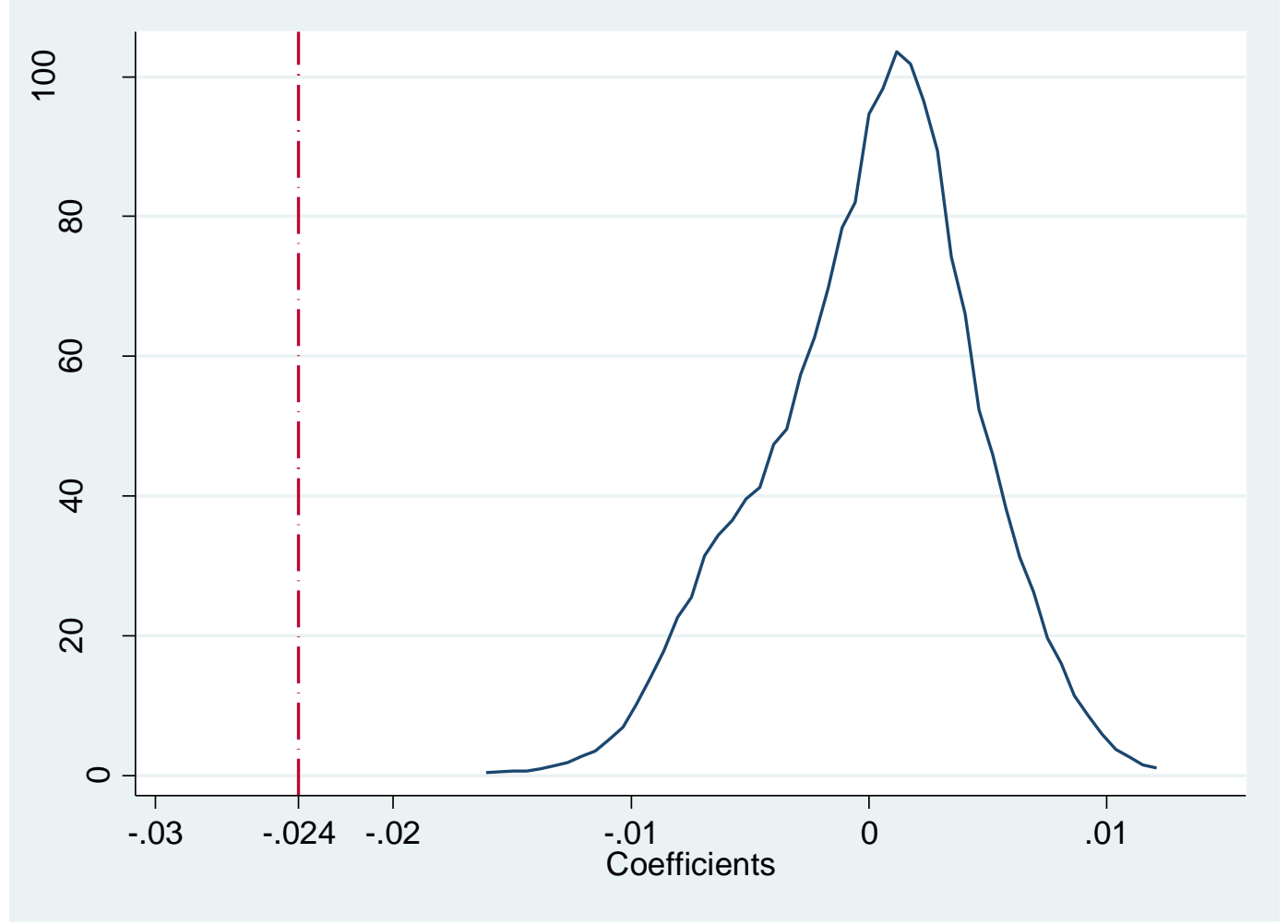

Notes: This figure shows the distribution of estimates from 500 times of randomization as well as our benchmark estimates (highlighted by the red line). The distribution of the estimates from the placebo is centered on zero, with a standard deviation of 0.0042 . 
Table 1: Effect of Machine Breakdown on Workers' Subsequent Productivity

\begin{tabular}{|c|c|c|c|c|c|c|}
\hline & (1) & $(2)$ & $(3)$ & (4) & $(5)$ & $(6)$ \\
\hline Machine(m') breaks down on day $d-1$ & $\begin{array}{c}-0.032 * * * \\
(0.008)\end{array}$ & $\begin{array}{c}-0.018 * * \\
(0.009)\end{array}$ & $\begin{array}{c}-0.024 * * \\
(0.011)\end{array}$ & & & $\begin{array}{l}-0.027 * \\
(0.016)\end{array}$ \\
\hline Repair time above sample median & & & & $\begin{array}{c}-0.030 * * \\
(0.014)\end{array}$ & & \\
\hline Repair time below sample median & & & & $\begin{array}{l}-0.014 \\
(0.015)\end{array}$ & & \\
\hline $\begin{array}{l}\text { Machine (m') of the other worker breaks down } \\
\text { on day } d-1\end{array}$ & & & & & $\begin{array}{c}0.003 \\
(0.012)\end{array}$ & \\
\hline $\operatorname{Machine}\left(\mathrm{m}^{\prime}\right)$ breaks down on day $d-2$ & & & & & & $\begin{array}{l}-0.011 \\
(0.009)\end{array}$ \\
\hline Machine(m') breaks down on day $d-3$ & & & & & & $\begin{array}{c}-0.014 * * \\
(0.007)\end{array}$ \\
\hline \multicolumn{7}{|l|}{ Machine $(m)$ characteristics } \\
\hline Same machine on day $\mathrm{d}$ and $d-1(\mathrm{~m}=\mathrm{m} ')$ & & $\begin{array}{c}0.027 * * * \\
(0.007)\end{array}$ & $\begin{array}{c}0.026 * * * \\
(0.007)\end{array}$ & $\begin{array}{c}0.026 * * * \\
(0.007)\end{array}$ & $\begin{array}{c}0.024 * * * \\
(0.008)\end{array}$ & $\begin{array}{c}0.019 * * \\
(0.007)\end{array}$ \\
\hline Productivity on day $d-1$ & & $\begin{array}{c}0.004 \\
(0.015)\end{array}$ & $\begin{array}{c}0.006 \\
(0.015)\end{array}$ & $\begin{array}{c}0.008 \\
(0.015)\end{array}$ & $\begin{array}{c}0.007 \\
(0.014)\end{array}$ & $\begin{array}{c}0.010 \\
(0.029)\end{array}$ \\
\hline Machine m breaks down on day $d-1$ & & $\begin{array}{l}-0.003 \\
(0.006)\end{array}$ & $\begin{array}{l}-0.002 \\
(0.007)\end{array}$ & $\begin{array}{l}-0.003 \\
(0.007)\end{array}$ & $\begin{array}{c}-0.018 * * \\
(0.008)\end{array}$ & $\begin{array}{l}-0.005 \\
(0.007)\end{array}$ \\
\hline \multicolumn{7}{|l|}{ Worker characteristics } \\
\hline Hours worked on day $d$ & & $\begin{array}{c}0.011 * * * \\
(0.002)\end{array}$ & $\begin{array}{c}0.012 * * * \\
(0.003)\end{array}$ & $\begin{array}{c}0.012 * * * \\
(0.003)\end{array}$ & $\begin{array}{c}0.015 * * * \\
(0.003)\end{array}$ & $\begin{array}{c}0.014 * * * \\
(0.003)\end{array}$ \\
\hline Productivity on day $d-1$ & & $\begin{array}{c}0.018 \\
(0.021)\end{array}$ & $\begin{array}{c}0.014 \\
(0.027)\end{array}$ & $\begin{array}{c}0.014 \\
(0.027)\end{array}$ & $\begin{array}{c}0.046 * * \\
(0.023)\end{array}$ & $\begin{array}{l}-0.002 \\
(0.051)\end{array}$ \\
\hline $\begin{array}{l}\text { Average day } d \text { productivity of workers } \\
\text { producing p' on day } d-1\end{array}$ & & $\begin{array}{c}0.683 * * * \\
(0.146)\end{array}$ & $\begin{array}{c}0.706 * * * \\
(0.151)\end{array}$ & $\begin{array}{c}0.707 * * * \\
(0.151)\end{array}$ & $\begin{array}{c}0.691 * * * \\
(0.183)\end{array}$ & $\begin{array}{c}0.635^{* * *} \\
(0.154)\end{array}$ \\
\hline Historical breakdown frequency & & & $\begin{array}{c}0.023 \\
(0.055)\end{array}$ & $\begin{array}{c}0.023 \\
(0.055)\end{array}$ & $\begin{array}{c}-0.029 * * \\
(0.014)\end{array}$ & $\begin{array}{c}0.027 \\
(0.059)\end{array}$ \\
\hline Historical breakdown frequency squared & & & $\begin{array}{l}-0.086 \\
(0.102)\end{array}$ & $\begin{array}{l}-0.085 \\
(0.102)\end{array}$ & $\begin{array}{c}0.016 \\
(0.014)\end{array}$ & $\begin{array}{l}-0.092 \\
(0.108)\end{array}$ \\
\hline Historical breakdown frequency*Breakdown & & & $\begin{array}{l}-0.056 \\
(0.070)\end{array}$ & $\begin{array}{l}-0.058 \\
(0.070)\end{array}$ & $\begin{array}{l}-0.023 \\
(0.049)\end{array}$ & $\begin{array}{l}-0.039 \\
(0.083)\end{array}$ \\
\hline $\begin{array}{l}\text { Historical breakdown frequency squared } \\
\text { *Breakdown }\end{array}$ & & & $\begin{array}{c}0.127 \\
(0.107)\end{array}$ & $\begin{array}{c}0.128 \\
(0.107)\end{array}$ & $\begin{array}{c}0.041 \\
(0.044)\end{array}$ & $\begin{array}{c}0.125 \\
(0.123)\end{array}$ \\
\hline Individual FE & Y & Y & $\mathrm{Y}$ & Y & Y & $\mathrm{Y}$ \\
\hline Product*Day FE & Y & $\mathrm{Y}$ & Y & $\mathrm{Y}$ & $\mathrm{Y}$ & $\mathrm{Y}$ \\
\hline Product*Machine FE & $\mathrm{Y}$ & $\mathrm{Y}$ & Y & Y & Y & $\mathrm{Y}$ \\
\hline Observations & 20,157 & 19,200 & 18,634 & 18,634 & 15,019 & 15,768 \\
\hline
\end{tabular}

Notes: This table reports the estimated effects of machine breakdown on workers' second day productivity together with a number of robustness checks. The dependent variable is a worker's over-target percentage of output, i.e., (output-target)/target. Values in parentheses are robust standard errors, clustered at worker level. *, **, and *** represent statistical significance at p-value of $0.10,0.05$, and 0.01 , respectively. 
Table 2: Tests on Proficiency and Emotional Reactions

\begin{tabular}{lcc}
\hline \hline & $(1)$ & $(2)$ \\
\hline Machine(m') breaks down on day $d-1$ & $-0.023^{* *}$ & $-0.023^{* *}$ \\
& $(0.012)$ & $(0.012)$ \\
(Absent on day $d-2)$ & -0.004 & \\
& $(0.006)$ & \\
(Absent on day $d-2) *($ Break down on day $d-1)$ & 0.017 & \\
& $(0.020)$ & \\
(first time of breakdown)*(Break down on day $d-1)$ & & -0.012 \\
& & $(0.020)$ \\
Controls & & $\mathrm{Y}$ \\
Individual FE & $\mathrm{Y}$ & $\mathrm{Y}$ \\
Product*Day FE & $\mathrm{Y}$ & $\mathrm{Y}$ \\
Product*Machine FE & $\mathrm{Y}$ & $\mathrm{Y}$ \\
Observations & 18,578 & 18,634 \\
\hline \hline
\end{tabular}

Notes: This table reports tests on two possible explanations. The dependent variable is a worker's over-target percentage of output, i.e., (output-target)/target. Controls are the same as in Table 1, including: dummy indicating same machine on day $\mathrm{d}$ and $\mathrm{d}-1(\mathrm{~m}=\mathrm{m}$ '), machine $\mathrm{m}$ 's productivity on day $\mathrm{d}-1$, whether machine $\mathrm{m}$ broke down on day d-1, worker's hours worked on day d, worker productivity on day d-1, the average day d productivity of workers producing p' on day d-1, a second order polynomial function of machine m's breakdown frequency in the past 5 days. Values in parentheses are robust standard errors, clustered at worker level. *, **, and *** represent statistical significance at p-value of $0.10,0.05$, and 0.01 , respectively. 
Table 3: Heterogeneous Effects and Social Comparison

\begin{tabular}{|c|c|c|c|c|}
\hline & (1) & (2) & (3) & (4) \\
\hline \multirow[t]{2}{*}{ Machine(m') breaks down on day d-1 } & $-0.027 * *$ & -0.019 & $-0.036 * * *$ & $-0.033 *$ \\
\hline & $(0.011)$ & $(0.016)$ & $(0.013)$ & $(0.018)$ \\
\hline \multirow[t]{2}{*}{ Male*(Break down on day d-1) } & -0.017 & & & \\
\hline & $(0.012)$ & & & \\
\hline \multirow[t]{2}{*}{ Age*(Break down on day d-1) } & & -0.0008 & & \\
\hline & & $(0.001)$ & & \\
\hline \multirow[t]{2}{*}{ Local (Fujian) Resident*(Break down on day $d-1$ ) } & & & 0.014 & \\
\hline & & & $(0.012)$ & \\
\hline \multirow[t]{2}{*}{ Breakdown Percentage on day $d-1$} & & & & -0.016 \\
\hline & & & & $(0.046)$ \\
\hline (Breakdown percentage on day $d-1$ ) & & & & 0.047 \\
\hline$*($ Break down on day d-1) & & & & $(0.049)$ \\
\hline Controls & $\mathrm{Y}$ & Y & $\mathrm{Y}$ & $\mathrm{Y}$ \\
\hline Individual FE & $\mathrm{Y}$ & $\mathrm{Y}$ & $\mathrm{Y}$ & $\mathrm{Y}$ \\
\hline Product*Day FE & $\mathrm{Y}$ & $\mathrm{Y}$ & $\mathrm{Y}$ & $\mathrm{Y}$ \\
\hline Product*Machine FE & $\mathrm{Y}$ & $\mathrm{Y}$ & $\mathrm{Y}$ & Y \\
\hline Observations & 13,064 & 13,064 & 13,064 & 18,634 \\
\hline
\end{tabular}

Notes: This table reports the results of heterogeneous effects. The dependent variable is a worker's over-target percentage of output, i.e., (output-target)/target. Controls are the same as in Table 1, including: dummy indicating same machine on day $\mathrm{d}$ and $\mathrm{d}-1(\mathrm{~m}=\mathrm{m}$ '), machine $\mathrm{m}$ 's productivity on day $\mathrm{d}-1$, whether machine $\mathrm{m}$ broke down on day $\mathrm{d}-1$, worker's hours worked on day d, worker productivity on day $\mathrm{d}-1$, the average day $\mathrm{d}$ productivity of workers producing $\mathrm{p}$ ' on day $\mathrm{d}-1$, a second order polynomial function of machine m's breakdown frequency in the past 5 days. Values in parentheses are robust standard errors, clustered at worker level. *, **, and *** represent statistical significance at p-value of $0.10,0.05$, and 0.01 , respectively. 


\section{Appendix Figure A1: Average Repair Hours for Machine Breakdowns}

(October 2012 - March 2014)

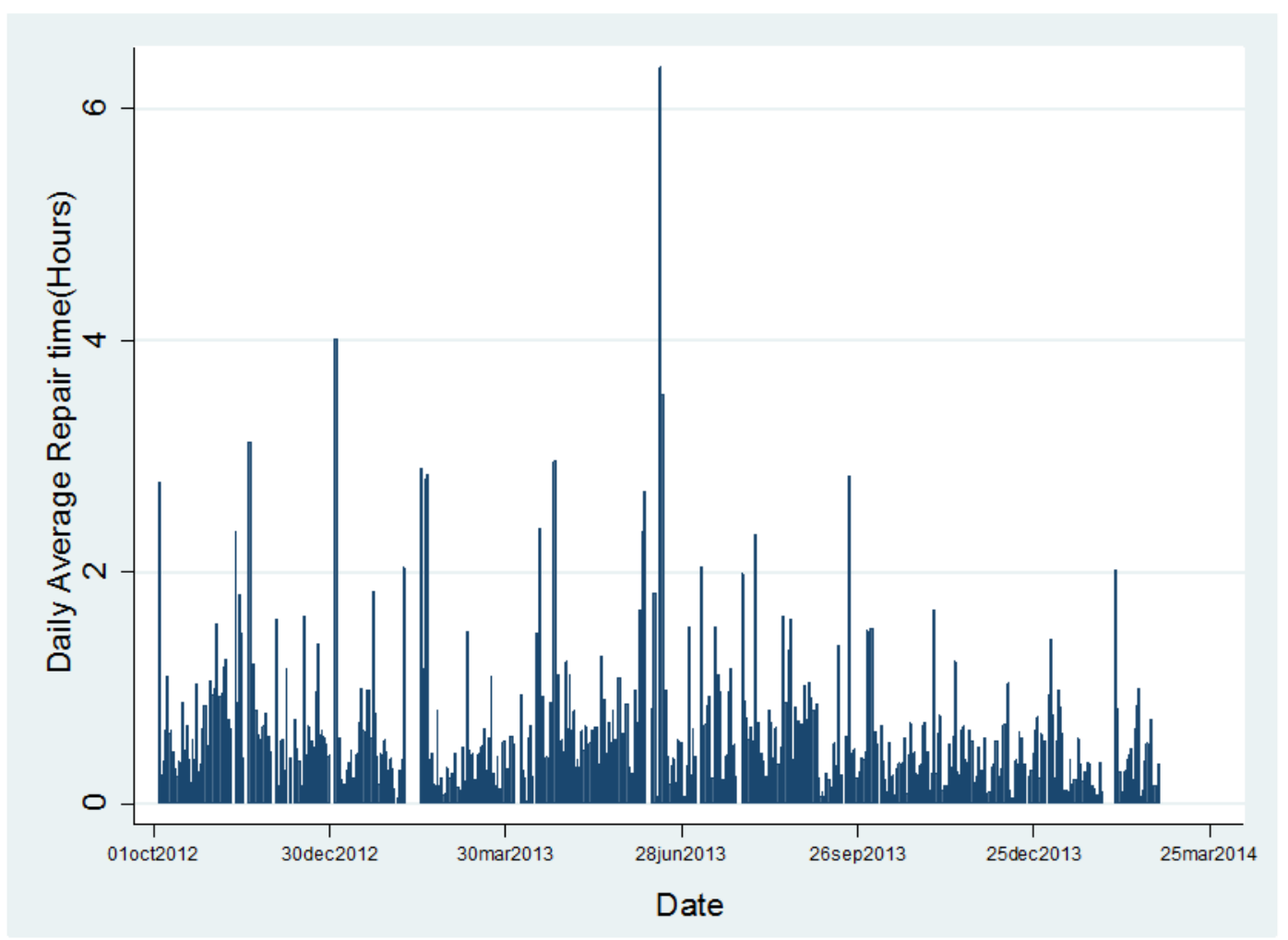

Notes: The figure plots the average repair time (in hours) for machine breakdown for each workday between October 2012 and March 2014. 


\section{Appendix Figure A2: Distribution of Breakdown Duration}

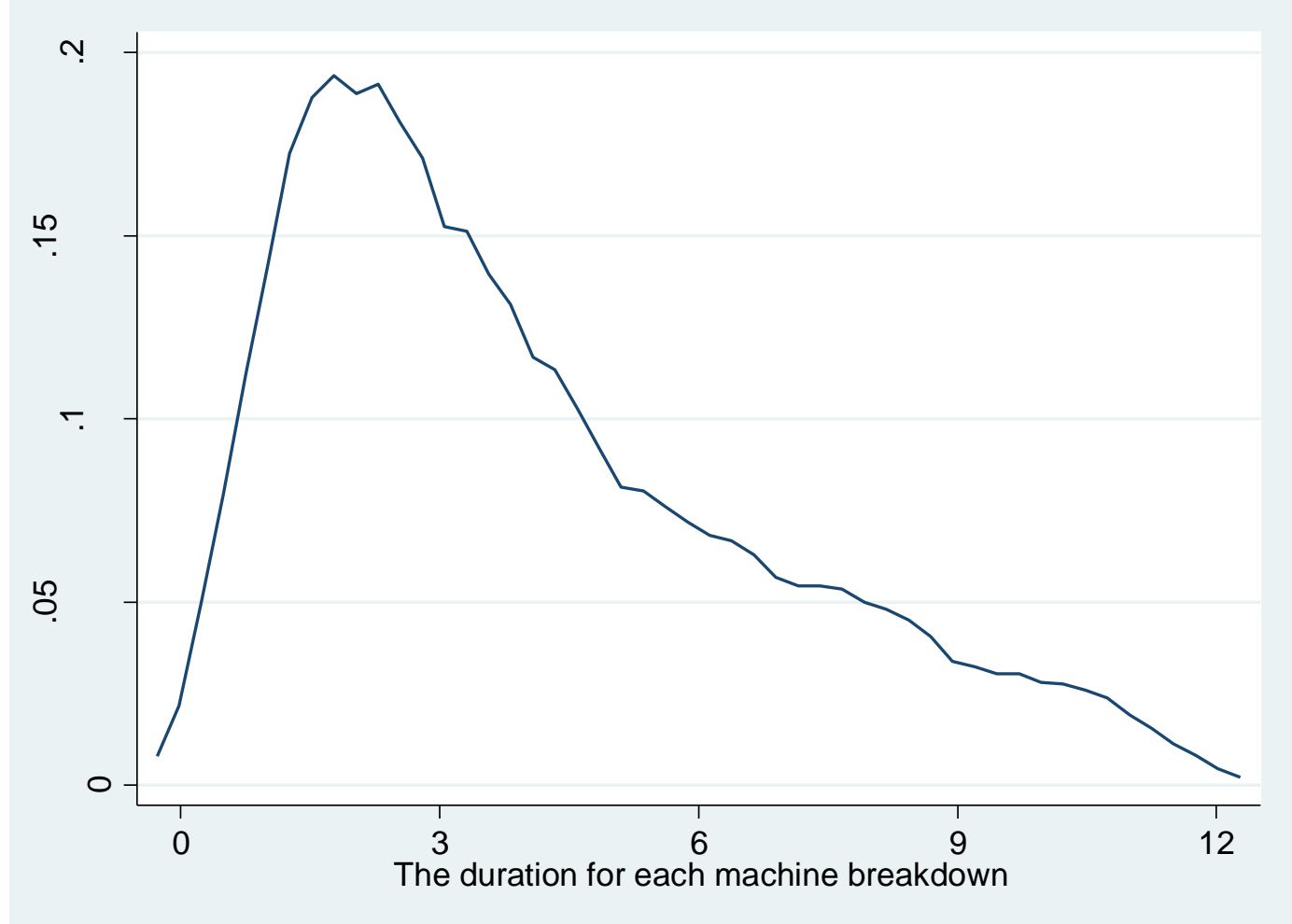

Notes: The figure shows the distribution of the duration (in hours) of machine breakdowns. 
(1)

(3)

\begin{tabular}{lcccc} 
& Absent on day $d$ & Excl Abnormal day & Past 3 days & Past 7 days \\
\hline Machine(m') break down on day $d-1$ & -0.001 & $-0.023 * *$ & $-0.020 * *$ & -0.019 \\
& $(0.011)$ & $(0.011)$ & $(0.010)$ & $\mathrm{Y}$ \\
Controls & & & $\mathrm{Y}$ & $\mathrm{Y}$ \\
Individual FE & $\mathrm{Y}$ & $\mathrm{Y}$ & $\mathrm{Y}$ & $\mathrm{Y}$ \\
Product p'*(Day-1) FE & $\mathrm{Y}$ & $\mathrm{Y}$ & $\mathrm{Y}$ & $\mathrm{Y}$ \\
Product p'*Machine m' FE & $\mathrm{Y}$ & $\mathrm{Y}$ & 18,817 & 18,469 \\
Observations & $\mathrm{Y}$ & 18,629 & $\mathrm{Y}$ & $\mathrm{Y}$ \\
\hline \hline
\end{tabular}

Notes: This table reports the results of four robustness checks. Column (1) reports the estimated effect of machine breakdown on workers' absence from work on the following day. The dependent variable is a dummy variable that equals one if the worker is absent from and zero otherwise. Column (2) presents the results using sample excluding the workday where all machines broke down. Column (3) and (4) present the results using historical frequency in the past 3 and 7 days, respectively, instead of 5 days as used in our preferred specification from Column (3), Table 1. Values in parentheses are robust standard errors. $* * *$, and $* * *$ represent statistical significance at $p$-value of $0.10,0.05$, and 0.01 , respectively. 
Appendix Table A2: Factors for Machine Breakdowns

\begin{tabular}{|c|c|}
\hline & (1) \\
\hline MAX Temperature & $\begin{array}{c}0.003 * * \\
(0.001)\end{array}$ \\
\hline MIN Temperature & $\begin{array}{l}-0.002 \\
(0.002)\end{array}$ \\
\hline Precipitation & $\begin{array}{c}-0.001 * * * \\
(0.000)\end{array}$ \\
\hline Dew Point Temperature & $\begin{array}{c}0.000 \\
(0.001)\end{array}$ \\
\hline Wind Speed & $\begin{array}{c}0.001 \\
(0.002)\end{array}$ \\
\hline Station Pressure & $\begin{array}{l}0.000 * \\
(0.000)\end{array}$ \\
\hline year month 201211 & $\begin{array}{c}0.076 * * * \\
(0.023)\end{array}$ \\
\hline year month 201212 & $\begin{array}{c}0.033 \\
(0.026)\end{array}$ \\
\hline year month 201301 & $\begin{array}{c}0.026 \\
(0.030)\end{array}$ \\
\hline year month 201302 & $\begin{array}{c}0.013 \\
(0.039)\end{array}$ \\
\hline year month 201303 & $\begin{array}{l}-0.041 \\
(0.025)\end{array}$ \\
\hline year month 201304 & $\begin{array}{c}0.046 \\
(0.030)\end{array}$ \\
\hline year month 201305 & $\begin{array}{c}0.060 * * * \\
(0.021)\end{array}$ \\
\hline year month 201306 & $\begin{array}{c}0.037 \\
(0.033)\end{array}$ \\
\hline year month 201307 & $\begin{array}{c}0.035 \\
(0.025)\end{array}$ \\
\hline year month 201308 & $\begin{array}{c}0.002 \\
(0.022)\end{array}$ \\
\hline year month 201309 & $\begin{array}{c}-0.043 * \\
(0.023)\end{array}$ \\
\hline year month 201310 & $\begin{array}{l}-0.034 \\
(0.022)\end{array}$ \\
\hline year month 201311 & $\begin{array}{l}-0.016 \\
(0.020)\end{array}$ \\
\hline year month 201312 & $\begin{array}{c}-0.039 * \\
(0.024)\end{array}$ \\
\hline year month 201401 & $\begin{array}{l}-0.036 \\
(0.029)\end{array}$ \\
\hline
\end{tabular}




\begin{tabular}{cc}
\hline \hline year month 201402 & 0.007 \\
& $(0.035)$ \\
& $0.037^{* *}$ \\
& $(0.017)$ \\
& $0.030^{*}$ \\
Tuenday & $(0.017)$ \\
& $0.033^{*}$ \\
Wednesday & $(0.019)$ \\
& 0.016 \\
Thursday & $(0.015)$ \\
& 0.003 \\
Friday & $(0.015)$ \\
& $-0.025^{*}$ \\
Saturday & $(0.015)$
\end{tabular}

Observations 472

Notes: This table reports the estimates on the determinants of machine breakdown. The dependent variable is a dummy that is one if the machine breaks down and zero otherwise. Values in parentheses are robust standard errors. *, **, and *** represent statistical significance at $p$-value of $0.10,0.05$, and 0.01 , respectively. 